\title{
Synthesis, characterization and photo-epoxidation performance of Au-loaded photocatalysts
}

\author{
VAN-HUY NGUYEN, HSIANG-YU CHAN and JEFFREY C S WU* \\ Department of Chemical Engineering, National Taiwan University, Taipei 10617, Taiwan \\ e-mail: cswu@ntu.edu.tw
}

MS received 7 November 2012; revised 11 February 2013; accepted 5 April 2013

\begin{abstract}
Titanium silicalite-1 (TS-1) was synthesized by hydrothermal crystallization. Au-loaded TS-1 (Au/TS-1) was prepared by the photo-deposition method. The prepared photocatalysts have been fully characterized by Raman, Brunauer-Emmett-Teller (BET), transmission electron microscopy, scanning electron microscopy, X-ray diffraction, X-ray photoelectron spectroscopy, and ultraviolet visible light spectroscopy to reveal their structure, surface morphology and chemical composition. Photocatalytic activity of these photocatalysts was ascertained by gas phase photo-epoxidation of propylene-to-propylene oxide in the presence of molecular oxygen only under light irradiation. No sacrificial reductant such as hydrogen was used during the photoreaction. Au/TS-1 photocatalyst remained highly stable under reaction conditions. It is found that the increased $\mathrm{Ti}^{3+}$ sites due to the incorporation of Au will not only enhance the selectivity of the photocatalyst to form epoxide but also its stability during $\mathrm{C}_{3} \mathrm{H}_{6}$ conversion.
\end{abstract}

Keywords. Photo-epoxidation; propylene oxide; molecular oxygen; Au-loaded photocatalyst; titanium silicalite (TS-1).

\section{Introduction}

For the last 60 years, the demand for chemicals worldwide has reached an unprecedented level as development of the third world countries continues. For instance, propylene oxide (PO), the second-most valuable chemical intermediate, has become increasingly important to the chemical industry. ${ }^{1-3}$ It has been estimated that the global PO consumption reached 6.0 million tons (2009) from 3.9 million tons (1991). An annual average growth of over $7 \%$ was forecasted from 2009 to 2014 as demand recovered after the economic crisis. $^{4}$

$$
\mathrm{CH}_{3} \mathrm{CHCH}_{2}+\mathrm{O}_{2}+\mathrm{H}_{2} \underset{\text { high temp., high pressure }}{\longrightarrow} \mathrm{CH}_{3} \mathrm{CHCH}_{2} \mathrm{O}+\mathrm{H}_{2} \mathrm{O}
$$

It is realized that propylene epoxidation with $\mathrm{H}_{2}-\mathrm{O}_{2}$ mixture using mesoporous and nanoporous $\mathrm{Ti}$ support modified by noble metals such as $\mathrm{Au}$ and $\mathrm{Ag}$ has received more and more attention due to its excellent catalyst stability as well as activity (eq. 1). ${ }^{5-10}$ Earlier efforts using $\mathrm{Au} / \mathrm{TiO}_{2}$ catalyst by Hayashi et al. ${ }^{6}$ have demonstrated high selectivity $(>90 \%)$ towards $\mathrm{PO}$ at low propylene conversion $(\sim 1 \%)$ at $303-393 \mathrm{~K}$. Cumaranatunge and Delgass ${ }^{7}$ found that Au-loaded titanium silicalite-1 (Au/TS-1) catalyst can improve the reactivity which achieved 5-10\% propylene conversion

*For correspondence with a selectivity of $75-85 \%$ towards $\mathrm{PO}$ at $473 \mathrm{~K}$. However, it is important to mention that the extra thermal energy needed for the reaction and the safety concern of hydrogen will make such a route only a provisional solution.

$$
2 \mathrm{CH}_{3} \mathrm{CHCH}_{2}+\mathrm{O}_{2} \underset{\text { mild conditions }}{\stackrel{\text { Photocatalyst }}{\longrightarrow}} 2 \mathrm{CH}_{3} \mathrm{CHCHC}_{2} \mathrm{O}
$$

Recently, there is an increasing interest in the direct gas-phase photocatalytic epoxidation (eq. 2). ${ }^{11-15}$ In this approach, the concept of green chemistry, the most desirable process, is adopted in which light energy is 
used as a driving force to activate the epoxidation reaction in the presence of molecular oxygen only. Photoepoxidation process holds the key for sustainable development because it has several advantages such as low energy consumption, free pollutant emission, and generation of eco-friendly end products since the process can be activated by photons at ambient temperature.

Much effort has been devoted to improve selective photo-epoxidation by using noble metal loaded photocatalyst in mild conditions. Recently, we have reported the use of TS-1 photocatalyst to promote photoepoxidation of propylene using only molecular oxygen in a flow reactor system. ${ }^{11}$ In this study, Au-loaded TS-1 and $\mathrm{TiO}_{2}$ were synthesized and fully characterized by Raman, BET, transmission electron microscopy (TEM), scanning electron microscopy (SEM), X-ray diffraction (XRD), X-ray photoelectron spectroscopy (XPS) and ultraviolet visible light spectroscopy (UV-vis). Selective photo-epoxidation of propylene was performed over P25, TS-1, $\mathrm{Au} / \mathrm{TiO}_{2}$ and $\mathrm{Au} / \mathrm{TS}-1$ with only molecular oxygen.

\section{Experimental}

\subsection{Preparation of photocatalysts}

TS-1 support material was synthesized according to the literature. ${ }^{16}$ Basically, it was obtained from hydrothermal crystallization of gel which was formed from the reaction of tetraethylorthosilicate (TEOS, Aldrich, 98\%) and titanium (IV) tetrabutoxide (TBOT, Alfa Aesar, 98\%) in the presence of tetrapropylammonium hydroxide (TPAOH, 20\% in water, Fluka).

Au-loaded photocatalysts were prepared by photodeposition method, which was adopted by Yang et al. ${ }^{17}$ TS-1 and Degussa P25 titania were used as support photocatalysts. First, $\mathrm{HAuCl}_{4}$ solution and support photocatalysts were mixed together and adjusted to $\mathrm{pH}=5.5$ by using $0.1 \mathrm{M}$ of $\mathrm{Na}_{2} \mathrm{CO}_{3}$. Then, 200-W mercury-arc lamp (filter: $320-500 \mathrm{~nm}$, intensity: $0.1 \mathrm{~W} . \mathrm{cm}^{-2}$ ) was used to irradiate the mixture for 120 min with stirring. The photo-deposition reaction was conducted under room temperature to avoid aggregation of gold. ${ }^{18}$ The
Au loading was 0.5 and $0.1 \mathrm{wt} \%$ for $\mathrm{TiO}_{2}$ and TS- 1 photocatalysts, respectively. The colour of the solution, initially deep purple, became clear after photo-deposition indicating that $\mathrm{Au}$ was almost loaded on $\mathrm{TiO}_{2}$ and TS-1. Finally, the mixture was filtered and washed in deionized water before drying in an oven at $393 \mathrm{~K}$ and calcining in air at $773 \mathrm{~K}$ for $5 \mathrm{~h}$.

\subsection{Photocatalyst characterization}

The prepared photocatalysts were fully characterized by powder XRD (X-ray-M03XHF, Ultima IV) to verify their crystalline structure. All XRD peaks were checked and assigned to known crystalline phases. Light absorption of the photocatalyst was revealed by UV-vis (Varian Cary-100). $\mathrm{BaSO}_{4}$ was used as a standard baseline sample. XPS was carried out on the Thermo Theta Probe instrument to determine the chemical composition of the photocatalyst and the chemical state of various species. SEM was conducted on the Nova Nano SEM 230 instrument. TEM was performed on the Hitachi H-7100 electron microscope instrument. BET surface area was measured with the Micromeritics, ASAP 2000. Raman spectra of the photocatalysts were obtained by the single-monochromator Renishaw Raman System 1000 equipped with a thermoelectrically cooled charge coupled device (CCD) detector $\left(-73^{\circ} \mathrm{C}\right)$ and holographic edge filter. The samples were excited with 514-nm Ar line. Spectral resolution was $2 \mathrm{~cm}^{-1}$, and spectrum acquisition time was $300 \mathrm{~s}$ for each sample.

\subsection{Photo-epoxidation reaction}

Figure 1 shows the apparatus for carrying out photoepoxidation of propylene-to-propylene oxide. First, $0.02 \mathrm{~g}$ of photocatalyst was packed in a photo-reactor with a quartz window for light transmission. The UVA (320-500 nm) in 200-W mercury-arc lamp was used as the irradiation source and guided to the photoreactor by an optical fibre. The photo-reactor was placed on a hot plate in case heating was required. The reaction was carried out with a reactant gas mixture

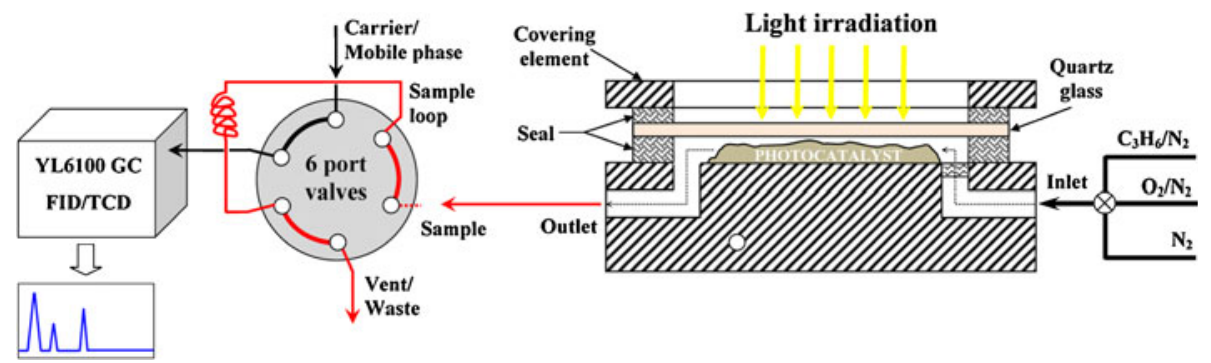

Figure 1. Apparatus for gas-phase photocatalytic epoxidation of propylene. 
of $\mathrm{C}_{3} \mathrm{H}_{6}: \mathrm{O}_{2}: \mathrm{N}_{2}=1: 1: 18$, and $\mathrm{GHSV}=6,000 \mathrm{~h}^{-1}$. The stream was analysed online and periodically using a gas chromatograph (Young Lin, YL6100 GC) equipped with a flame ionization detector (FID), a thermal conductivity detector (TCD) and both Molecular Sieve5A and Porapak-N columns. Propylene conversion rate and product selectivity in the reaction were calculated directly by eqs (3) and (4) as defined below.

$\mathrm{C}_{3} \mathrm{H}_{6}$ conv. rate $=\sum$ rate of products converted to $\mathrm{C}_{3}$

Product selectivity $=100 \% \times$ product converted to $\mathrm{C}_{3} /$ all products converted to $\mathrm{C}_{3}$

\section{Results and discussion}

\subsection{Photocatalyst characterization}

3.1a Morphology and crystal structures: Crystalline structure of the photocatalysts was identified by using
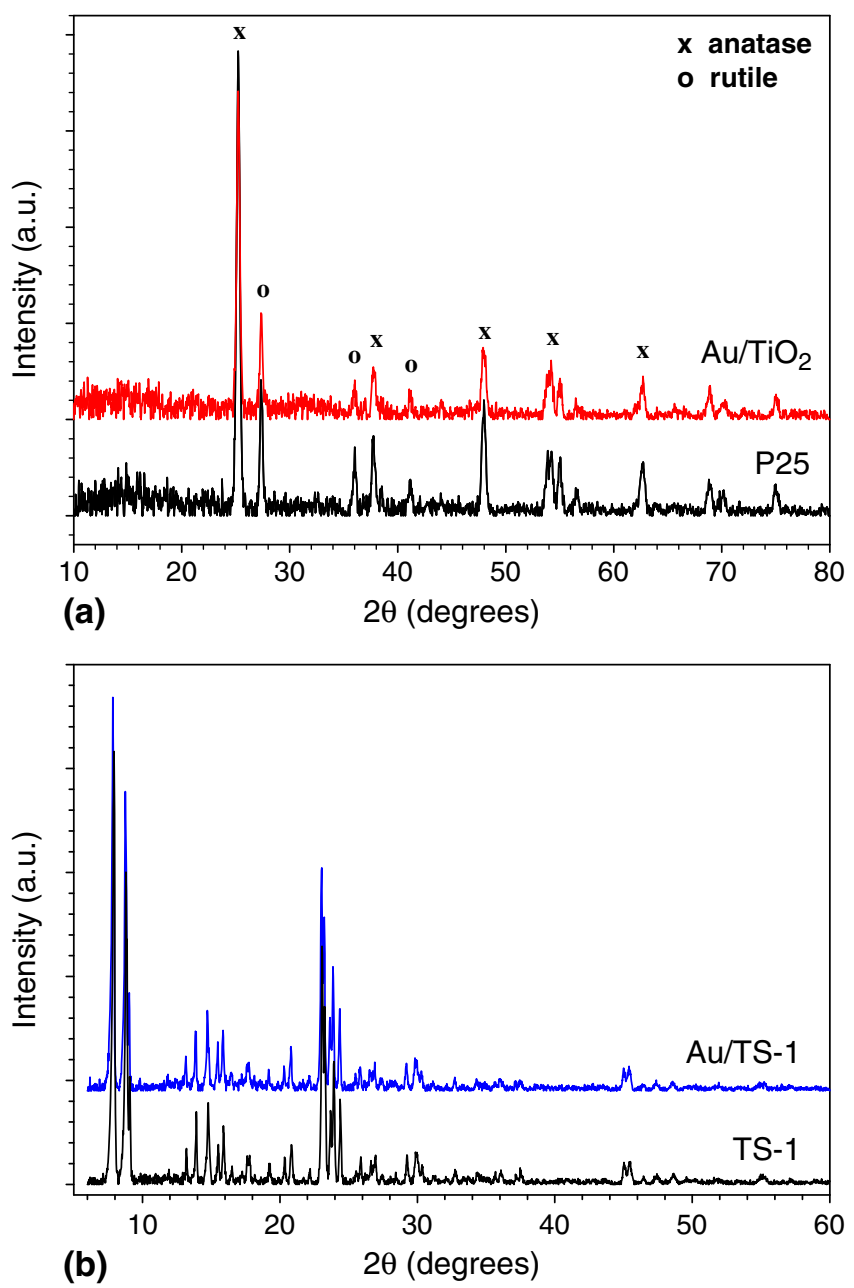

Figure 2. X-ray diffraction patterns of photocatalysts: (a) P25 and $\mathrm{Au} / \mathrm{TiO}_{2}$; (b) TS-1 and Au/TS-1.
XRD. In figure 2(a), photocatalysts containing $\mathrm{TiO}_{2}$ show obvious XRD peaks corresponding to anatase and rutile phase as expected in P25. The obtained diffraction patterns as seen in figure 2(b) are consistent with those reported in literature. ${ }^{11,16}$ The presence of single diffractive peaks at $2 \theta=24.3^{\circ}$ in the XRD pattern indicates a change from monoclinic symmetry of Silicalite-1 (S-1) to orthorhombic symmetry of titanium silicalite-1 (TS-1). The $2 \theta$ values at which major peaks appear for both $\mathrm{Au}-\mathrm{TiO}_{2}$ and $\mathrm{Au} / \mathrm{TS}-1$ are found to be almost the same as those of P25 and TS-1, respectively, except for the intensities of the peaks. It suggests that loading of $\mathrm{Au}$ does not affect crystal structure, but it may alter crystallinity of the photocatalysts. In addition, no peak corresponding to gold can be observed from XRD analysis. This may be explained by the fact that Au concentration used in this study is extreme low $(\leq 0.5 \%)$, making the signal of gold peaks too weak to be detected.

Figure 3 shows Raman spectra of $\mathrm{P} 25, \mathrm{Au} / \mathrm{TiO}_{2}$, TS-1 and Au/TS-1 photocatalysts when excited by
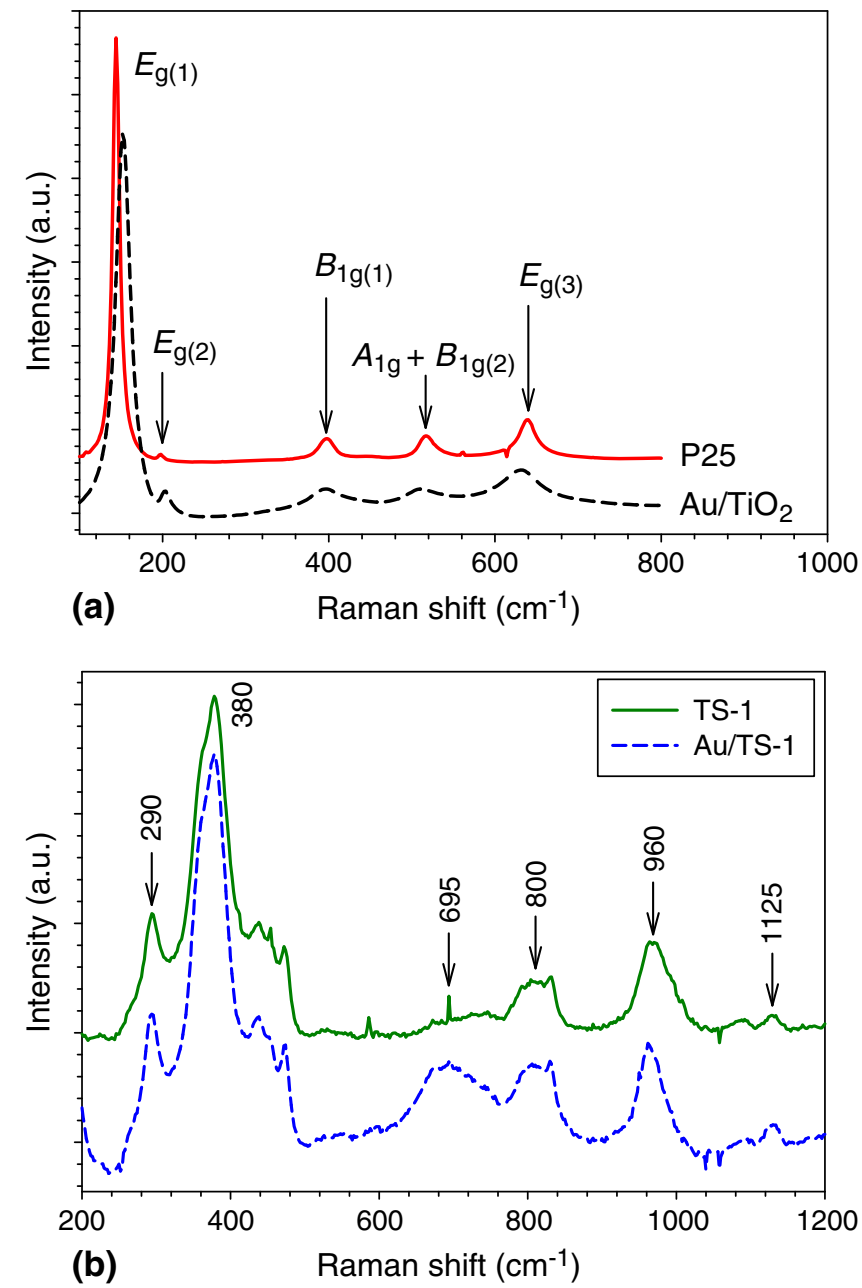

Figure 3. Raman spectra of photocatalysts: (a) P25 and $\mathrm{Au} / \mathrm{TiO}_{2}$; (b) TS-1 and Au/TS-1. 
wavelength of $514 \mathrm{~nm}$. Figure 3(a) shows the presence of six Raman-active fundamentals in the vibrational spectrum: three $\mathrm{E}_{\mathrm{g}}$ modes centred around 149, 201 and $638 \mathrm{~cm}^{-1}$ (designated here $\mathrm{E}_{\mathrm{g}(1)}, \mathrm{E}_{\mathrm{g}(2)}$ and $\mathrm{E}_{\mathrm{g}(3)}$, respectively), two $\mathrm{B}_{1 \mathrm{~g}}$ modes at 396 and $514 \mathrm{~cm}^{-1}$ (designated $\mathrm{B}_{1 \mathrm{~g}(1)}$ and $\left.\mathrm{B}_{\lg (2)}\right)$, and an $\mathrm{A}_{1 \mathrm{~g}}$ mode at $514 \mathrm{~cm}^{-1} .19$ Figure 3(b) shows Raman spectrum of Au/TS-1, which is almost identical to that of TS-1. Both of them show the characteristic Raman bands of MFI structures (290,
380 and $800 \mathrm{~cm}^{-1}$ ) and two Ti-specific bands (960 and $\left.1125 \mathrm{~cm}^{-1}\right)$, typically found for TS-1. Among the two Ti-specific bands, the $1125 \mathrm{~cm}^{-1}$ band corresponds to the totally symmetric stretching mode of the $\left[\mathrm{Ti}(\mathrm{OSi})_{4}\right]$ unit, while the $960 \mathrm{~cm}^{-1}$ band is a combination of three asymmetric stretching modes of the same unit. ${ }^{20}$ The Raman results further confirm that loading of $\mathrm{Au}$ does not affect crystal structure of TS- 1 and $\mathrm{TiO}_{2}$ supports, which is consistent with the XRD results.

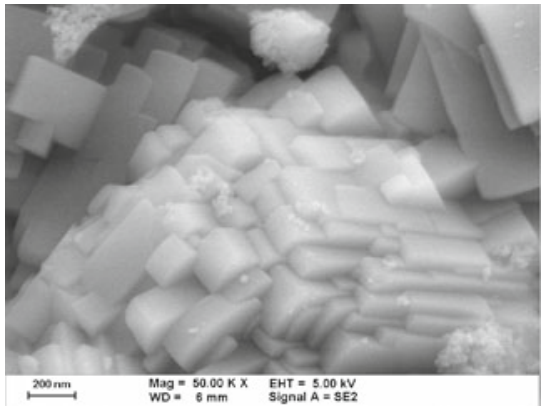

(a)

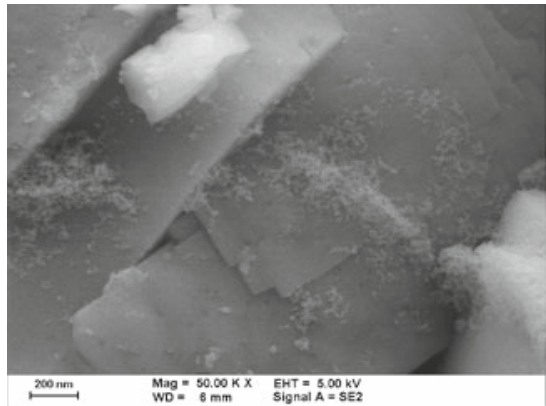

(b)

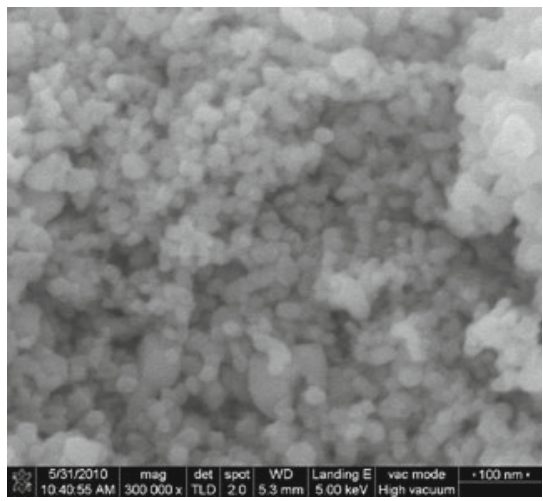

(c)

Figure 4. SEM micrographs of photocatalysts: (a) TS-1, (b) Au/TS-1 and (c) $\mathrm{Au} / \mathrm{TiO}_{2}$.

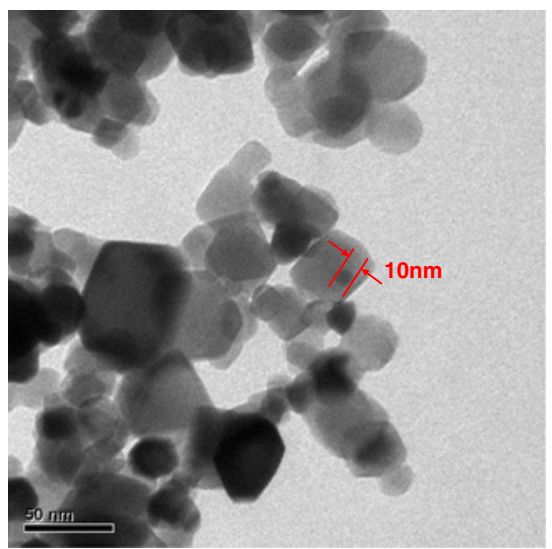

(a)

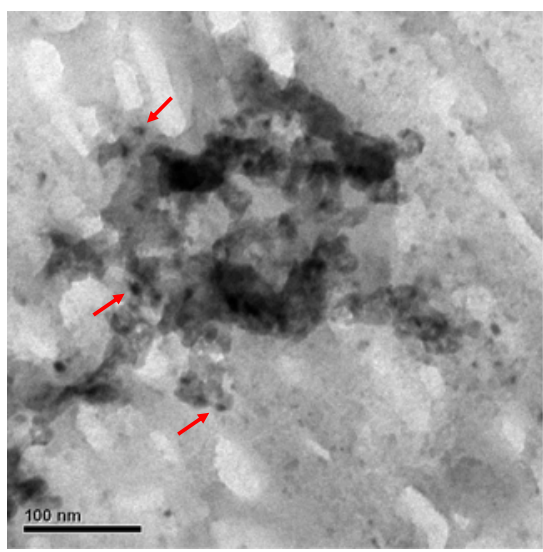

(b)

Figure 5. TEM micrographs of photocatalysts: (a) $\mathrm{Au} / \mathrm{TiO}_{2}$ and (b) $\mathrm{Au} / \mathrm{TS}-1$. 
Table 1. Results of propylene photo-epoxidation over various photocatalysts. ${ }^{\text {(a) }}$

\begin{tabular}{|c|c|c|c|c|c|c|c|c|c|c|c|}
\hline \multirow[t]{2}{*}{ Entry } & \multirow[t]{2}{*}{ Catalysts } & \multirow{2}{*}{$\begin{array}{l}\text { Au loading } \\
\text { (wt } \%)\end{array}$} & \multirow{2}{*}{$\begin{array}{c}\text { BET } \\
\left(\mathrm{m}^{2} \cdot \mathrm{g}^{-1}\right)\end{array}$} & \multirow{2}{*}{$\begin{array}{c}\mathrm{C}_{3} \mathrm{H}_{6} \text { conv. rate }{ }^{(\mathrm{b})} \\
\left(\mu \mathrm{mol} \cdot \mathrm{g}^{-1} \cdot \mathrm{h}^{-1}\right)\end{array}$} & \multirow{2}{*}{$\begin{array}{l}\text { PO formation rate } \\
\left(\mu \mathrm{mol} . \mathrm{g}^{-1} \cdot \mathrm{h}^{-1}\right)\end{array}$} & \multicolumn{6}{|c|}{ Selectivity $^{(\mathrm{c})}(\%)$} \\
\hline & & & & & & $\overline{\mathrm{AA}}$ & $\mathrm{PO}$ & $\mathrm{PA}$ & $\mathrm{AC}$ & $\mathrm{ROH}$ & $\mathrm{CO}_{2}$ \\
\hline 1 & P25 & - & 50.0 & 130.0 & 0.13 & 5.3 & 0.1 & 1.1 & 5.9 & 0.2 & 87.4 \\
\hline 2 & $\mathrm{Au} / \mathrm{TiO}_{2}$ & 0.5 & 47.6 & 141.8 & 1.56 & 14.8 & 1.1 & 1.1 & 7.5 & 0.4 & 75.1 \\
\hline 3 & TS-1 & - & 369 & 54.2 & 23.67 & 21.5 & 43.7 & 26.9 & 7.9 & ND & ND \\
\hline 4 & $\mathrm{Au} / \mathrm{TS}-1$ & 0.1 & 377 & 56.1 & 30.35 & 12.7 & 54.3 & 27.1 & 5.9 & ND & ND \\
\hline
\end{tabular}

(a) The data is the mean value obtained on stream after $12 \mathrm{~h}$ (except $4 \mathrm{~h}$ for entries 1 and 2 ) | Reaction conditions: feed gas, $\mathrm{C}_{3} \mathrm{H}_{6}: \mathrm{O}_{2}: \mathrm{N}_{2}=1: 1: 18$ in vol. $\%$ at GHSV=6,000 $\mathrm{h}^{-1}$, light intensity: $0.1 \mathrm{~mW} . \mathrm{cm}^{-2}$ (except $0.2 \mathrm{~mW}^{-\mathrm{cm}^{-2}}$ for entries 1 and 2); reaction temperature: $323 \mathrm{~K}$ (except $298 \mathrm{~K}$ for entry 1) | PO: Propylene oxide; PA: Propionaldehyde; AC: Acetone; AA: Acetaldehyde | ND: not detected.

${ }^{\text {(b) }} \mathrm{C}_{3} \mathrm{H}_{6}$ conversion rate $=\sum$ rate of all products converted to $\mathrm{C} 3$

${ }^{\text {(c) }}$ Product selectivity $=\frac{100 \% \times \text { mol of the formation product converted to } \mathrm{C}_{3}}{\text { mol of all products converted to } \mathrm{C}_{3}}$

Figure 4(a) and (b) shows the SEM micrograph of TS-1 and Au/TS-1 photocatalyst, respectively, indicating that small amount of $\mathrm{TiO}_{2}$ is aggregated on the $\mathrm{SiO}_{2}$ surface in some regions. Figure 4(c) shows the SEM micrograph of $\mathrm{Au} / \mathrm{TiO}_{2}$ with the average particle size of roughly $20 \mathrm{~nm}$ for $\mathrm{TiO}_{2}$.

TEM was used to identify $\mathrm{Au}$ particles loaded on both $\mathrm{TiO}_{2}$ and TS-1 photocatalysts in this study. From the TEM results shown in figure 5, Au particles are observed on both $\mathrm{TiO}_{2}$ and TS-1. The dark-field TEM image reveals that $\mathrm{Au}$ particles were dispersed in $\mathrm{TiO}_{2}$ and $\mathrm{TiO}_{2}$ matrix of TS-1 with a mean particle size of $10-12 \mathrm{~nm}$.

The BET surface areas of TS-1 and $\mathrm{TiO}_{2}$ support materials, before and after depositing $\mathrm{Au}$, are shown in table 1. Au loading on these supports does not bring any significant change in their surface areas.

3.1b UV-vis analysis: UV-vis absorption spectra of different photocatalysts are shown in figure 6. P25 is a commercial $\mathrm{TiO}_{2}$ photocatalyst that absorbs only UV light $(<380 \mathrm{~nm})$. Au loading on $\mathrm{TiO}_{2}$ photocatalysts significantly affects the light absorption property of bare $\mathrm{TiO}_{2}$, i.e., the appearance of an absorption band ranging from 500 to $700 \mathrm{~nm}$, which is attributed to surface plasmon resonance (SPR) effect of noble metals. ${ }^{21}$ Spectra of TS-1 supports with the absorption at about 200-400 nm are widely used to confirm the presence of isolated Ti(IV) in the framework position as well as the extra-framework titanium-containing species. ${ }^{11,22}$ For the spectrum of $\mathrm{Au} / \mathrm{TS}-1$, a small peak corresponding to SPR is also observed (inset of figure 6).

The band gap of TS- 1 and Au/TS-1 photocatalyst is calculated by extrapolating the absorption edge onto the energy axis. First, the absorption data is fitted to

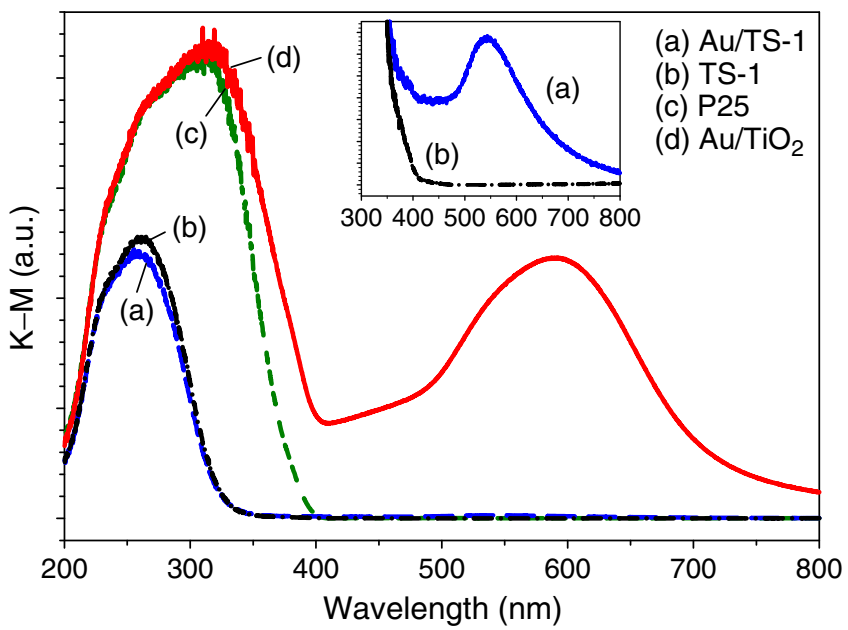

Figure 6. UV-vis absorption spectra of photocatalysts.

equations for both direct and indirect band gap transitions. Figure $7\left(\right.$ a) shows the $[F(R) h v]^{2}$ versus $h v$ plot for a direct transition and figure 7(b) shows the $[F(R) h v]^{1 / 2}$ versus $h v$ plot for an indirect transition, where $F(R)$ is the absorption coefficient, $h v=(1239 / \lambda)$ $\mathrm{eV}$ is the photon energy, and $\lambda$ is the wavelength $(\mathrm{nm})$. The value of $h v$ extrapolated to $F(R)=0$ gives an absorption energy, which corresponds to a band gap $E_{\mathrm{g}}$. As seen in figure 7(a) for direct transition, both TS-1 and Au/TS-1 show a perfect fit and the extrapolation yields band gap $\left(E_{\mathrm{g}}\right)$ values of 4.01 and $4.06 \mathrm{eV}$, respectively. On the other hand, the band gap estimated from the less-perfect-fit indirect transition is 3.56 and $3.51 \mathrm{eV}$ for TS-1 and Au/TS-1, respectively. Reddya et al. ${ }^{23}$ suggested that a direct band gap transition would result in a more efficient absorption of solar energy. 

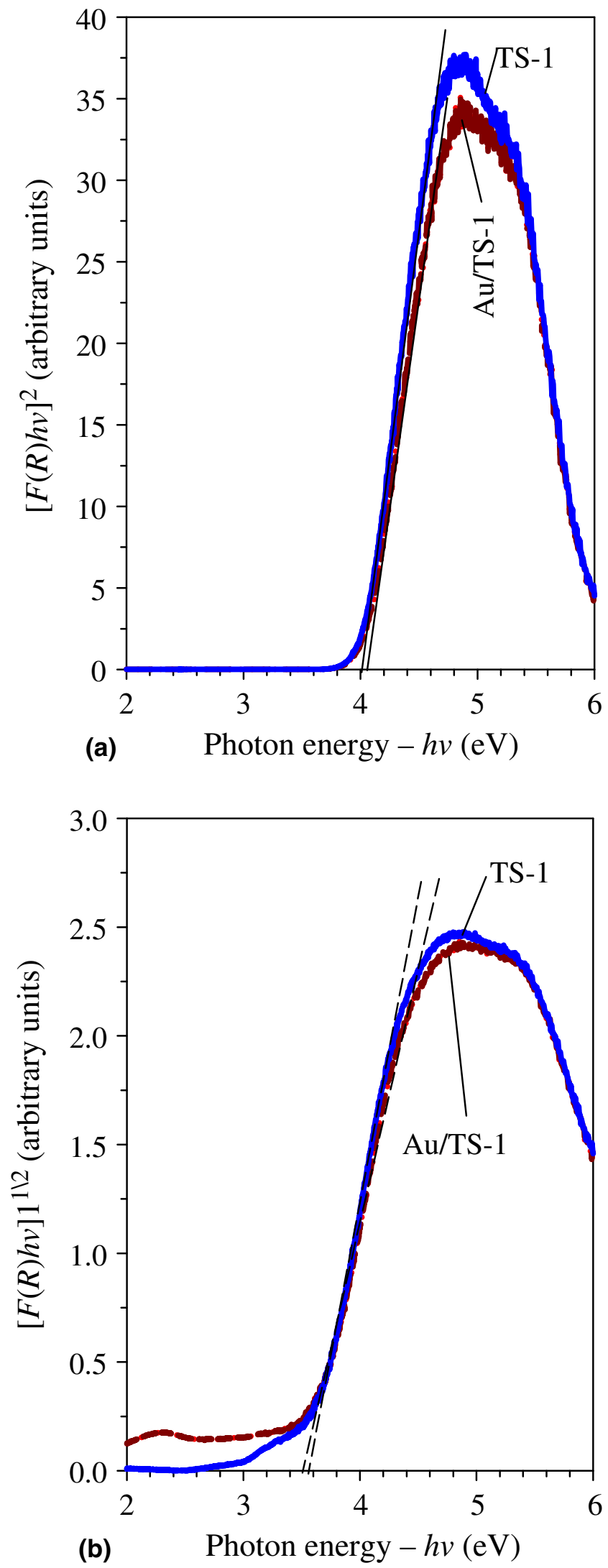

Figure 7. (a) Plot of $[F(R) h v]^{2}$ versus $h v$ for direct transition and (b) Plot of $[F(R) h v]^{1 / 2}$ versus $h v$ for indirect transition. Band gaps $E_{\mathrm{g}}$ are obtained by extrapolation to $F(R)=0$. 3.1c XPS analysis: Figure 8 shows Ti $2 p$ and $\mathrm{Si} 2 \mathrm{p}$ XPS spectra of both Au/TS-1 and TS-1 photocatalysts before and after photoreaction. It can be seen that these two samples before and after the reaction have shown identical surface chemical composition, suggesting that the photocatalysts are highly stable during the photoreaction. ${ }^{11}$ Figure 9 shows Ti $2 p$ XPS spectra for the photocatalysts. For TS-1 support, peaks corresponding to the transitions of $\mathrm{Ti} 2 \mathrm{p}_{1 / 2}$ and $\mathrm{Ti} 2 \mathrm{p}_{3 / 2}$ are clearly observed. The oxidation state for Ti $2 \mathrm{p}_{1 / 2}$ and Ti $2 \mathrm{p}_{3 / 2}$ are $3+$ and $4+$, respectively, with the former assigned to extra-framework titania and the latter to framework titanium. ${ }^{24,25}$ There is a significant amount of $\mathrm{Ti}$ in the oxidation state of $3+$ rather than the oxidation state of $4+$ observed in the Ti $2 \mathrm{p}$ XPS spectra of Au/TS-1 $(67.4 \%)$ and TS-1 (49.5\%) photocatalysts. Sinha et al. ${ }^{26}$ mentioned that molecular oxygen can be taken up by a $\mathrm{Ti}^{3+}$ cation site $\left(\mathrm{Ti}^{4+}-\mathrm{O}-\mathrm{Au}^{0} \leftrightarrow \mathrm{Ti}^{3+}-\mathrm{O}-\mathrm{Au}^{+}\right)$ and is activated to a negatively charged molecular oxygen species. Hence, the loading of Au on TS- 1 in this study can increase the amount of $\mathrm{Ti}$ with oxidation state of $3+$ in TS-1, favouring selective photo-epoxidation. It suggests that reduced titanium species is crucial in photo-efficiency, in agreement with the result in previous studies on photo-degradation of methyl orange and phenol. ${ }^{25}$ Furthermore, it is worth mentioning that the $\mathrm{Ti}^{3+}$ sites in photocatalysts are highly stable in air under irradiation, which will not induce any activity degradation. ${ }^{27}$ This further supports the highly stable photo-activity results observed in this study. The XPS spectrum of $\mathrm{Au} 4 \mathrm{f}$ was also measured; however, no peak corresponding to $\mathrm{Au} 4 \mathrm{f}$ was detected. This may be due to the weak signal, which is lower than the detection limit of the XPS ( $\sim 1 \%$ detection limit).

\subsection{Photocatalytic epoxidation of propylene}

We re-assessed the direct gas-phase photo-epoxidation of propylene via molecular oxygen by using various kinds of photocatalysts. From the results, no activity was observed either in the absence of photocatalysts with UV-irradiation or with photocatalysts in the absence of UV-irradiation, confirming that the epoxidation that occurs over photocatalysts is mainly photocatalytic epoxidation.

Table 1 summarizes the product formation rate and product selectivity. It was interesting to find that $\mathrm{Au}$ loading not only promoted the conversion rate of propylene but also improved the selectivity of epoxide formation in the photocatalytic epoxidation. Among the photocatalysts tested, Au/TS-1 shows the best performance. The PO formation rate of $\mathrm{Au} / \mathrm{TS}-1$ is 

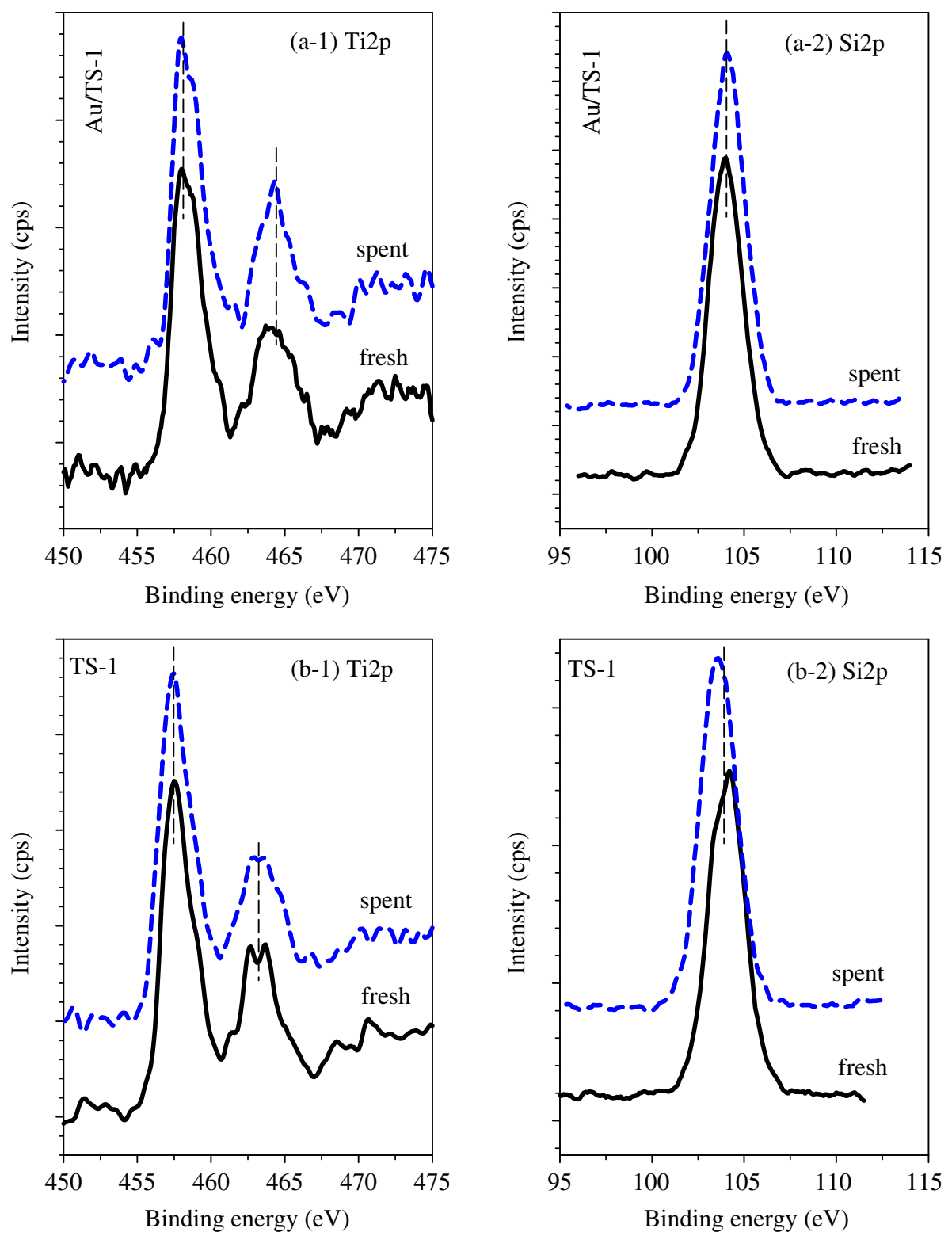

Figure 8. X-ray photoelectron spectra of Au/TS-1 and TS-1 photocatalysts before and after the reaction. Au/TS-1: (a-1) Ti 2p and (a-2) Si 2p; TS-1: (b-1) Ti 2p and (b-2) Si 2 p.

$30.35 \mu \mathrm{mol} . \mathrm{g}^{-1} \cdot \mathrm{h}^{-1}$, an improvement of $28 \%$ comparing with that of TS-1. However, in the case of $\mathrm{Au} / \mathrm{TiO}_{2}$ photocatalyst, most of $\mathrm{C}_{3} \mathrm{H}_{6}$ is still converted to $\mathrm{CO}_{2}$ (75.1\% selectivity). In this study, the percentage of $\mathrm{C}_{3} \mathrm{H}_{6}$ conversion is in the range of $0.02-0.03 \%$.

Figure 10 shows the time-dependent behaviour of selectivity for the formation of various products over TS-1 and Au/TS-1 photocatalysts. At the initial stage of the reaction, very high acetaldehyde (AA) selectivity $(70 \%$ and $55 \%)$ can be obtained. It then decreases and reaches steady state at $20 \%$ and $10 \%$ for TS- 1 and $\mathrm{Au} / \mathrm{TS}-1$, respectively. The initial increase in AA selectivity is probably due to the presence of large amount of multi-coordinated Ti centres (Ti-O-Ti) in TS- 1 support at the beginning. Stangland et al. ${ }^{28}$ mentioned that when decrease in Ti-O-Ti entities occur, significant improvement in selectivity towards epoxide will result due to the reduced cracking of propylene to AA. This result further supports the enhanced reliability observed for the photocatalyst. In addition, only photocatalysts with TS-1 support can provide relatively good stability in the selective epoxidation for a period of over $12-15 \mathrm{~h}$ to give PO selectivity of $43.7 \%$ and $54.3 \%$ for TS- 1 and $\mathrm{Au} / \mathrm{TS}-1$, respectively. Moreover, a very stable product distribution is achieved for both photocatalysts after $3 \mathrm{~h}$ of reaction. 

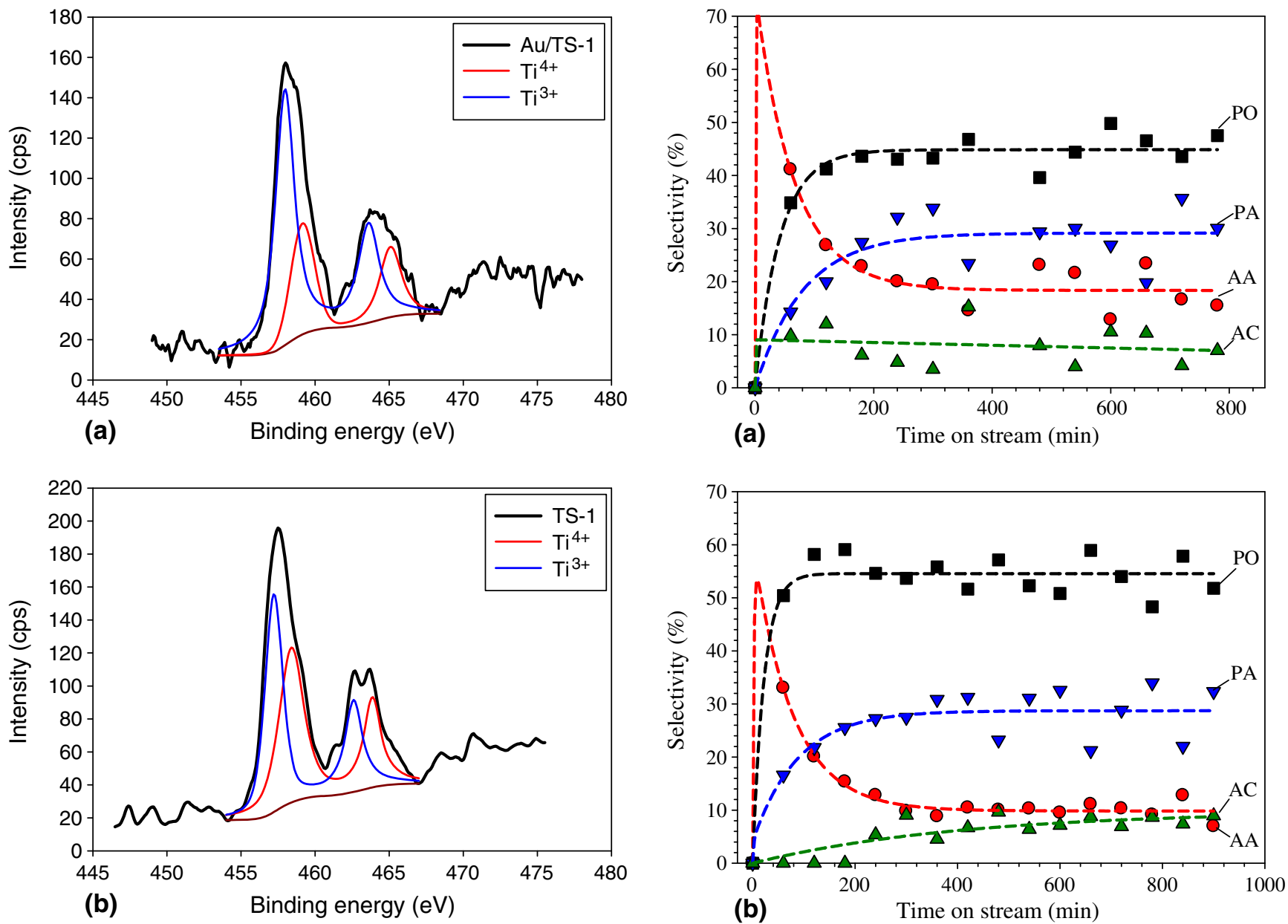

Figure 9. XPS spectra showing Ti 2p XPS peaks for (a) $\mathrm{Au} / \mathrm{TS}-1$ and (b) TS-1 photocatalysts. The spectra also show $\mathrm{Ti}^{3+}$ and $\mathrm{Ti}^{4+}$ peaks.

Figure 10. The time-dependent behaviour of selectivity for the formation of propylene oxide (PO), propionaldehyde (PA), acetaldehyde (AA) and acetone (AC) over (a) TS-1 and (b) Au/TS-1 photocatalysts at $323 \mathrm{~K}, 0.1 \mathrm{~mW} . \mathrm{cm}-2$.

It has been known that the major drawback of Auloaded photocatalyst, which is effective in epoxidation, is its fast deactivation. ${ }^{5}$ However, Au/TS- 1 photocatalyst still shows good stability in propylene conversion rate $\left(60 \mu \mathrm{mol} . \mathrm{g}^{-1} \cdot \mathrm{h}^{-1}\right)$ after $15 \mathrm{~h}$ of reaction as shown in figure 11, which is in agreement with the XPS results reported previously. We have mentioned that the $\mathrm{Ti}^{3+}$ sites in photocatalysts, which favour selective photo-epoxidation, are highly stable in air under irradiation and will not induce any activity degradation. As a result, good stability in $\mathrm{C}_{3} \mathrm{H}_{6}$ conversion can be achieved. This also implies that Au plays a crucial role in photo-epoxidation over the Au/TS-1 photocatalyst.

Recently, many studies have agreed that hydroperoxide intermediate species, which is responsible for selective epoxidation, are formed in the epoxidation of propylene using $\mathrm{H}_{2}-\mathrm{O}_{2}$ mixtures over Au-loaded photocatalysts. . $^{3,5,13,16}$ The key factor determining the selective epoxidation reaction is the size of Au particles, i.e., very small $\mathrm{Au}$ particles $(2-5 \mathrm{~nm})$ are the most

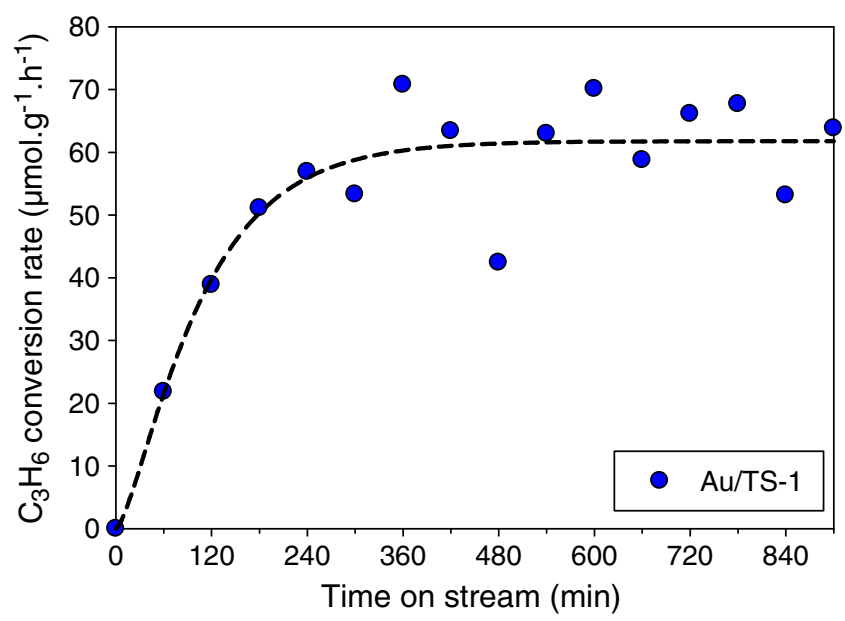

Figure 11. Time-dependent behaviour of $\mathrm{C}_{3} \mathrm{H}_{6}$ conversion rate over Au/TS-1 photocatalyst at $323 \mathrm{~K}, 0.1 \mathrm{~mW} . \mathrm{cm}^{-2}$. 
active due to the high coverage of oxygen or oxygenderived species, whereas large Au particles (>5 nm) are less active and tend to cause complete combustion of $\mathrm{C}_{3} \mathrm{H}_{6}$ to $\mathrm{CO}_{2} .{ }^{5,29}$ In this study, we have shown that noble metal loaded photocatalysts can exhibit good selectivity towards epoxide formation in the presence of only molecular oxygen. However, contributions of $\mathrm{Au}$ in epoxidation without a sacrificial reductant such as $\mathrm{H}_{2}$ are still a matter of debate. ${ }^{30}$ Rojluechai et al. ${ }^{31}$ suggested that oxygen species, which is responsible for selective epoxidation, are formed at the interface of $\mathrm{Au}$ particles and the supports. ${ }^{31}$ In this case, larger the size of Au particles ( $\geq 2 \mathrm{~nm}$ ), the more active sites the $\mathrm{Au}$ particles can provide to generate active oxygen species, which is in agreement with our results. For instance, photocatalyst with large Au particles (10-12 nm) can enhance selective epoxidation performance by providing more active sites for propylene epoxidation.

\section{Conclusion}

Au-loaded $\mathrm{TiO}_{2}$ and TS-1 photocatalysts are successfully prepared and fully characterized. We found that the Au/TS-1 photocatalysts not only exhibit enhanced selectivity towards epoxide formation $(54.3 \%$ selectivity), but also show improved stability in $\mathrm{C}_{3} \mathrm{H}_{6}$ conversion in which the products generated do not vary significantly with time. The enhancement in PO selectivity is due to the reduced cracking of propylene to AA, while the improvement in $\mathrm{C}_{3} \mathrm{H}_{6}$ conversion stability is due to the presence of highly stable $\mathrm{Ti}^{3+}$ sites, which will not induce any activity degradation. After $3 \mathrm{~h}$ of reaction, a very stable distribution of products can be achieved for both TS-1 and Au/TS-1 photocatalysts.

\section{Acknowledgements}

This research was financially supported by the National Science Council of Taiwan under contract number NSC 99-2923-E-002-002-MY2. The authors also thank Dr. Janusz Lasek from Institute for Chemical Processing of Coal, Poland for great help in designing the photo-reactor.

\section{References}

1. Nijhuis T A, Makkee M, Moulijn J A and Weckhuysen B M 2006 Ind. Eng. Chem. Res. 453447

2. Trent D L 2000 In Kirk-Othmer encyclopedia of chemical technology (Hoboken, NJ: John Wiley \& Sons, Inc)
3. Kahlich D, Wiechern U and Lindner J 2000 Ullmann's encyclopedia of industrial chemistry (Wiley-VCH Verlag $\mathrm{GmbH} \& \mathrm{Co} . \mathrm{KGaA}$ )

4. WP coverage of propylene oxide 2011 World Petrochemicals

5. Joshi A M, Taylor B, Cumaranatunge L, Thomson $\mathrm{K}$ T and Delgass W N 2008 In Mechanisms in homogeneous and heterogeneous epoxidation catalysis, Oyama S T (ed) chapter 11 (Amsterdam: Elsevier) p 315

6. Hayashi T, Tanaka K and Haruta M 1998 J. Catal. 178 566

7. Cumaranatunge L and Delgass W N 2005 J. Catal. 232 38

8. Nijhuis T A, Huizinga B J, Makkee M and Moulijn J A 1999 Ind. Eng. Chem. Res. 38884

9. Taylor B, Lauterbach J and Delgass W N 2005 Appl. Catal. A 291188

10. Wang R, Guo X, Wang X, Hao J, Li G and Xiu J 2004 Appl. Catal. A 2617

11. Nguyen V-H, Chan H-Y, Wu J C S and Bai H 2012 Chem. Eng. J. 179285

12. Nguyen V-H, Wu J C S and Bai H 2013 Catal. Commun. 3357

13. Amano F, Tanaka T 2005 Catal. Commun. 6269

14. Amano F, Tanaka T 2006 Chem. Lett. 35468

15. Yoshida H, Murata C and Hattori T 2000 J. Catal. 194 364

16. Khomane R B, Kulkarni B D, Paraskar A and Sainkar S R 2002 Mater. Chem. Phys. 7699

17. Yang Y-F, Sangeetha P and Chen Y-W 2009 Int. J. Hydrogen Energy 348912

18. Ivanova S, Pitchon V, Petit C, Herschbach H, Dorsselaer A V and Leize E 2006 Appl. Catal., A 298203

19. Zhang W F, He Y L, Zhang M S, Yin Z and Chen Q 2000 J. Phys. D: Appl. Phys. 33912

20. Bordiga S, Damin A, Bonino F, Ricchiardi G, Zecchina A, Tagliapietra R and Lamberti C 2003 Phys. Chem. Chem. Phys. 54390

21. Link S and El-Sayed M A 1999 J. Phys. Chem. B 103 8410

22. Vayssilov G N 1999 Cat. Rev. 39209

23. Reddy M K, Manorama S V and Reddy A R 2003 Mater. Chem. Phys. 78239

24. Vetter S, Schulz-Ekloff G, Kulawik K and Jaeger N I 1994 Chem. Eng. Technol. 17348

25. Naik B, Parida K M and Gopinath C S 2010 J. Phys. Chem. C 11419473

26. Sinha A K, Seelan S, Tsubota S and Haruta M 2004 Top. Catal. 2995

27. Zuo F, Wang L, Wu T, Zhang Z, Borchardt D and Feng P 2010 J. Am. Chem. Soc. 13211856

28. Stangland E E, Taylor B, Andres R P and Delgass W N 2005 J. Phys. Chem. B 1092321

29. Lu J, Zhang X, Bravo-Suárez J J, Bando K K, Fujitani T and Oyama S T 2007 J. Catal. 250350

30. Suo Z, Jin M, Lu J, Wei Z and Li C 2008 J. Nat. Gas Chem. 17184

31. Rojluechai S, Chavadej S, Schwank J W and Meeyoo V 2007 Catal. Commun. 857 